\title{
INTERPRETACIÓN E INSERCIÓN EN LA GLOBALIZACIÓN DEL CONFLICTO COLOMBIANO
}

(Recibido: Abril 20 de 2011 Aprobado: Agosto 3 de 2011)

Moisés Araque Ortiz**

\section{Resumen}

El presente texto es producto de la investigación titulada “El gobierno de Álvaro Uribe: Régimen autoritario en el contexto de la globalización de la seguridad". En esta segunda parte INTERPRETACIÓN EN LA GLOBALIZACIÓN DEL CONFLICTO COLOMBIANO se presentan situaciones con las cuales tiene que enfrentarse el Estado colombiano, como el narcotráfico y sus carteles, la pretensión de las FARC por crear un nuevo Estado (1999-2002), el surgimiento y poder del paramilitarismo, la soberanía y los sucesos internos que atentan contra ella.

\section{Palahras Have}

Narcotráfico, FARC, Paramilitares, Soberanía

\section{INTERPRETATION AND INSERTION IN THE GLOBALISATION OF THE COLOMBIAN EONFLICT}

\section{Ahstract}

The present text is the outcome of the research called "The government of Alvaro Uribe: Authoritarian regime in the context of the globalization of security". In this second part INTERPRETATION IN THE GLOBALISATION OF THE COLOMBIAN CONFLICT, the situations the country must face are presented, like drug trafficking and its cartels, the aspiration of the FARC to create a new State (1999-2002), the emergence and power of the paramilitary, sovereignty and the internal events that attempt against her.

\section{Keywords}

Drug trafficking, FARC, Paramilitary, Sovereignty

\footnotetext{
* Artículo de Investigación que surgió como resultado de la investigación realizada en torno al gobierno de Álvaro Uribe en el marco de la Maestría en estudios Políticos de la Universidad Javeriana de Bogotá. (II Parte)

** Profesor del Departamento de Humanidades de la Universidad Santo Tomás, experto en Historia de Colombia (UIS), Licenciado en Ciencias Sociales (U. de la Sabana) , Historiador (UIS), Especialista en Docencia Universitaria (USTA), Especialista en Educación para la Democracia (U. Manuela Beltrán), Magíster en Estudios Políticos (U. Javeriana).moisesaraque@yahoo.es
} 
Ante la situación de la debilidad del Estado para enfrentar a los grupos subversivos surgen los paramilitares con el fin de defender al Estado, con un despliegue de terror y violencia en todo el país. Así, Colombia entró a ser considerada como un problema transnacional y la mira del mundo se puso en ella, pero a su vez, el Estado colombiano busca la ayuda internacional para luchar contra estos flagelos, arriesgando su soberanía nacional, por la ayuda recibida de otros Estados.

La interdependencia y la integración de Colombia con el mundo (globalización) hacen que no esté sola, ya que hoy nadie funciona sin ayuda de otros y hay que estar en la aldea global. Por tanto, la política de la Seguridad Democrática programada por Álvaro Uribe Vélez, en la búsqueda de acabar con la violencia y el terrorismo tendrá que ser de resultados militares, con un gran despliegue económico (Plan Colombia, Plan Patriota).

\subsection{NARCOTRÁFICO CARTE- LES DE CALI-MEDELLÍN GO- BIERNO DE SAMPER}

Desde el punto de vista histórico Andrés López Restrepo lo describe cómo: “El narcotráfico es la última etapa de dos formas de ilegalidad: el contrabando y la violencia" (López, Restrepo, A. 2000, p. 97) cuando el 15 de septiembre de 1920 el Congreso colombiano aprobó la ley 11 para prohibir las drogas, empezó lo que posteriormente se convertiría en un problema nacional e internacional conocido como el narcotráfico, que con su poder económico permeó todos los ámbitos nacionales; se corrompió la clase política, las fuerzas armadas y cualquier autoridad; se puso precio a la vida, se negociaron elecciones y presidencias, y sus tentáculos pasaron fronteras, penetraron a otras economías mundiales; en el narcotráfico también se dio la globalización a partir de una organización con redes internacionales, donde la apertura de mercados y la administración con que se manejaba la envidiarían las mejores empresas transnacionales legales, quienes fueron sorprendidas por la rigurosidad en su organización, el manejo de la oferta y la demanda del pro-

"El narcotráfico
es la última
etapa de dos
formas de
ilegalidad: el
contrabando y la
violencia".
ducto; es decir, un mercado casi perfecto pero ilegal.

Las exportaciones crecieron en toneladas y Colombia se convirtió en un centro de narcotráfico mundial, invadió a los Estados Unidos con ampliación hacia los mercados europeos, con facilidad de rutas en sus comienzos y el uso del soborno, corrupción, violencia y terrorismo. Todo esto se convirtió en problema económico, político y social del cual no hemos podido resarcirnos.

Los narcotraficantes colombianos se enriquecieron abismalmente hacia los años 70; políticos y analistas defendían la legalización de las drogas por la gran afluencia de dinero y el poder que esto producía, sin desconocer la presencia de algunos políticos en esta organización. La década de los 80 hizo impensable esto y la discusión sobre la extradición hizo que los barones de la droga al no conseguir sus propósitos, emplearan las formas más aberrantes de violencia al implantar el narcoterrorismo a finales de los 80 y comienzos de los 90 con los carteles de Medellín, Cali y norte del Valle; se produjo la lucha por el poder y es así que en el enfrentamiento entre los carteles de Medellín y Cali fue aniquilado el jefe del cartel de Medellín Pablo Escobar y desmantelada su organización. En la actualidad hay un sin número de narcotraficantes que por norma de organización mantiene un bajo perfil con el fin de pasar desapercibidos y engañar a las autoridades. 
El poder económico del narcotráfico sacude continuamente la economía nacional, por ser subterráneo, oscuro, desconocido lo cual facilita la entrada al país de enormes cantidades de dólares que afectan el mercado interno por exceso de dinero circulante; Salomón Kalmanovitz describe: "entre 1987 cuando el solo negocio de la cocaína representó más de US $\$ 5000$ millones para los narcotraficantes colombianos y en la actualidad cuando alcanza los US $\$ 3000$ millones y cuenta con un abastecimiento muy mejorado hacia Europa y con precios todavía rentables" (Blanquert y Gros, 2002, p. 399). Otros agregados como el contrabando de licores según Kalmanovitz en 1988 se estimaba en US \$20,000 millones y la venta callejera de cigarrillos en US $\$ 100.000$ diarios, sin contar con otros ilegales.

Con ese dinero no solo se alteró la moneda circulante sino que se corrompió a todos los estamentos del Estado, desde el presidente (Ernesto Samper), fuerzas armadas, policías, jueces y hasta la Iglesia que recibió "donativos"; con ese dinero se encarecieron las tierras y las mejores pasarían a sus manos, la vivienda subió abismalmente, surgieron empleos no conocidos pero bien pagos como el del sicariato y el de guardaespaldas; rodó dinero fácil por todos los empleos ilegales que ellos dieron y que hoy todavía algunos añoran esa época de auge de los narcotraficantes. Hoy se ha incautado mucho dinero y algunas propiedades que han sido decomisadas se han convertido en un contratiempo pues las mismas autoridades no saben qué hacer con ellas ni cómo administrarlas.

Por otra parte, el narcotráfico se convierte en un problema político que penetra campañas de candidatos a los diferentes cargos de gobierno, hasta llegar a alcanzar curules y pertenecer o crear grupos políticos, como los de Pablo Escobar y Carlos Ledher que lograron amarrar a los dirigentes del Estado a los intereses de los narcotraficantes, como el caso de Alberto Santofimio Botero. Cuando los dirigentes políticos no se sometían a los intereses de los narcotraficantes eran asesinados como el Ministro Rodrigo Lara Bonilla, o el candidato a la presidencia Luis Carlos Galán. Por ello, no es raro encontrar un Congreso que se convierte en vocero de ellos para aprobar o desaprobar leyes que les favorezcan o perjudiquen. Francisco Leal Buitrago narra:

La política antidroga del gobierno de Samper tuvo muchos opositores, buena parte de ellos alentados por sus vínculos económicos y políticos con los narcotraficantes. La conducta del Congreso de la República fue notoria; varias de las iniciativas del ejecutivo fueron contrarrestadas o alteradas en el curso de los debates, inclusive con la abierta participación de grupos afines al gobierno. La discusión sobre extradición formo parte de esta situación (...). También hubo iniciativas del Congreso destinados a entrabar la acción contra el narcotráfico (Leal, Buitrago, F., 2002, p. 127)

Con un congreso arrodillado, una autoridad chantajeada, el apoyo económico dado a campañas políticas, los sobornos recibidos por la clase política y además, con la violencia demostrada por el narcoterrorismo, los narcotraficantes se sentían con un gran poder; de ahí que se opusieran a la extradición al aducir que era mejor una tumba acá en Colombia que la cárcel en el exterior. El caso de la participación política no era nuevo pues desde tiempo atrás se daba a través de varios periodos presidenciales, pero en el que más notorio se hizo y que posteriormente llevaría al proceso 8000 fue en la campaña de Pastrana - Samper, cuando después de los resultados de la primera vuelta, 29 de mayo de 1994, se diera un cabeza a cabeza, 2'623.210 de Samper contra 2'604.771 de la Nueva Fuerza Democrática de Andrés Pastrana. 
Lo que llevó a buscar fondos para financiar la $2^{a}$ vuelta pues los arcas de la campaña samperista ya se encontraba sin ellos y los costos eran imprevisibles pues era ganar o ganar y obtener la presidencia de la República para el periodo 1994-1998, por tanto, debía reestructurarse y conseguir los dineros necesarios para tan importante empresa asesorada por americanos y con personajes como Fernando Botero, -director de campaña-, José Antonio Vargas Lleras, Horacio Serpa, Juan Manuel Cristo, Luis Guillermo Vélez, Eduardo Mestre y Santiago Medina -tesorero de la campaña-, quien en declaraciones dadas a la fiscalía dentro del proceso 8000 , con relación a los dineros calientes en la campaña mostraría cómo estos llegaron al declarar:

La crisis era total. La campaña no tenía un centavo y fuera de eso yo tenía copado el cupo de los cuatro mil millones que autorizaba la ley (...) debía pedir cuatro mil millones también recordaba cómo a nombre del candidato se enviaba a la mafia un mensaje de 5 puntos dictado por Fernando Botero:

(...) Primero, el candidato Samper agradece el respaldo que ofrece $y$ valora su ayuda para llegar a ser presidente. Segundo, Ernesto Samper apoya la política de sometimiento y el proceso de negociación para superar el narcoterrorismo, la violencia y el tráfico de drogas. Tercero, respalda al fiscal Gustavo de Greiff en su manejo con los temas del narcoterrorismo. Cuarto, se compromete, como primera prioridad, en el primer semestre del gobierno a aclimatar el proceso de sometimiento del cartel de Cali. Quinto, estrictamente dentro del marco de la constitución y la ley, el nuevo gobierno hará todo lo que esté a su alcance para que esto llegue a su mejor término (Torres y Sarmiento, 1998, pp. 257-258)

Los cuatro mil millones los entregó la mafia a Fernando Botero quien, a su vez, autorizó que se le entregaran a Santiago Medina descrito en "Rehenes de la Mafia":

Los dineros que el doctor Botero autorizó que me entregaran fueron llevados por Alberto Giraldo y dos veces por Eduardo Mestre, directamente a mi casa, en cajas de cartón envueltas en papel de regalo de más o menos 500 millones cada una, eran seis cajas.

“No sólo estos dineros de los señores Rodríguez se recibieron. Hubo apoyo de personas que pertenecen a otros carteles de la droga. Los del cartel de la Costa entregaron sumas muy grandes de los departamentos del norte (...). Como el caso de la famosa avioneta de Córdoba que llevaba 180 millones de pesos en efectivo (...), el chileno Guillermo Pallomari con relación a la entrega de dineros a los postulantes al congreso señala: Personas que se postularon al Congreso que tuvieron reunión personal con Miguel Rodríguez o lo llamaban por teléfono que yo me haya dado cuenta son los siguientes: Armando Holguín Sarria, María Izquierdo (...) Carlos Abadía, Orlando Vásquez Velásquez (...) Gustavo Espinosa, Miguel Motoa, Francisco Jattin, Alberto Santofimio (...) Tiberio Villareal, Manuel Francisco Becerra, Rodrigo Garavito, Hugo Castro Borja, Ana Pechta (...) Jaime Lara." (Pp. 259263)

Todo lo conocido fue negado por el entonces presidente de

"Todo los colombianos Ernesto Samper quien afirmó habia sido con ironía y sarcasmo a sus espaldas". Hoy el espaldas" narcotráfico aún es un problema nacional e internacional pues de él se alimenta el terrorismo y se ha vuelto un negocio que todos quieren tener y que nadie quiere dejar; guerrilla, paramilitares, carteles, y delin- 
cuencia común son la peor desgracia que tiene que enfrentar el Estado y el pueblo colombiano, pues aunque se ha luchado contra él no deja de ser una mala hierba difícil de erradicar. El narcotráfico en el aspecto internacional nos ha estigmatizado como si todos fuéramos narcotraficantes e impide que seamos bienvenidos en muchos países del mundo. Colombia además de haberse convertido en un país exportador, presenta un grave problema social debido al consumo masivo que ha llegado a escuelas, colegios y universidades y originado otro mercado, el interior, y con él el incremento de la violencia y el terrorismo.

\subsection{EL CAGUÁN (1999-2002) UN INTENTO POR CREAR UN NUEVO ESTADO}

En el proceso de paz que se produjo durante el gobierno de Andrés Pastrana (1999-2002) las FARC pretendieron convertirse en un "ESTADO INDEPENDIEN$T E^{\prime \prime}$, lo que originó una crisis de soberanía nacional. Habría que preguntarse: ¿Por qué un Estado Independiente? Pero entonces: ¿Qué es el Estado? Es un concepto, abstracto y ambiguo y, por tanto, son muchas las definiciones que de él se dan; Weber, Bodin, Hobbes, Hegel, Bobbio y Nietzsche, entre otros, lo han tratado de definir: Weber: "Aquella comunidad humana que, dentro de un determinado (el $<<$ territorio $>>$ es elemento distintivo),

"Aquella comunidad

humana que, dentro de un determinado

(el $<<$ territorio $>>$ es elemento distintivo), reclama (con éxito) para sí el monopolio de la violencia física legítima" reclama (con éxito) para sí el monopolio de la violencia física legítima" (Weber, 1980, p. 83).

Nietzsche lo define:

El nombre que se da al más frío de todos los monstruos fríos. El Estado miente con toda frialdad y de su boca sale esta mentira: $<<$ yo, el Estado, soy el pueblo $>>$ (...) Estado Ilamo yo al lugar donde todos, buenos y malos, aseguran su perdición. Estado al lugar donde se llama $<<$ vida $>>$ al lento suicidarse de todos" (Nietzsche, 1982, pp. 72-73)

Bobbio escribe que una condición necesaria y suficiente para que exista un Estado es:

"Que en un territorio determinado haya un poder capaz de tomar decisiones y emitir mandatos correspondientes obligatorios para todos los que habitan en ese territorio y obedecido efectivamente por la gran mayoría de los destinatarios en la mayor parte que se requiera la obediencia; cualesquiera que sean las decisiones" (Bobbio, 1997, pp.129-130 )

Norbert Elias plantea como claves de la existencia de un Estado: "La constitución del monopolio fiscal y el monopolio de la violencia en el marco de un territorio" (Elias, 1989, p. 345 y ss)

Por tanto, un Estado debe tener una estructura interna, un territorio, un cuerpo de ciudadanos (nación), una sociedad civil; para la descripción que nos atañe se asume la definición de Michael Walzer: “Espacio de asociación humana sin coerción y también el conjunto de la trama de relaciones -formadas en nombre de la familia, la fe, los intereses y la ideología- que llenan ese espacio" (1994, p. 48) Recordar lo que definimos como democracia.

Se puede construir un concepto de Estado tomándolo como un territorio con una sociedad, con un conjunto de normas (Leyes), una administración justa, un uso legítimo de la fuerza coercitiva y un derecho de gentes "IUS Gentium" en la relación internacional con otros Esta- 
dos, en concordancia y en la búsqueda del bien común; todo esto equivale a soberanía nacional, es decir, unas relaciones internas y otras externas con otros Estados, con los cuales se firman pactos o tratados para una mejor convivencia internacional, todo con un fin común, el de conservarse (Razón de Estado).

La política de las FARC ha sido la búsqueda de poder por medio de la violencia, pretenden aplicar el aforismo Maoísta: “El poder nace del fusil " y aquel de "Nosotros no queremos la guerra, nosotros queremos la paz, pero para hacer la paz, hay que hacer la guerra"; por esta razón de poseer un medio coercitivo (armas), y ante la coyuntura de la crisis del Estado, encontraron el momento propicio para llegar a un proceso de paz negociado, que los llevaría a pretender convertirse en un "Estado en formación como lo confirmó Simón Trinidad, integrante del secretariado de las FARC-EP, pero, para ello necesitaban reconocimiento político por parte del Estado (status político) y a nivel internacional; una dialéctica que ya manejaban y que le daría excelentes resultados en la mesa de negociación: un territorio delimitado, una fuerza coercitiva de dos características; una psicológica (amenaza, chantaje, soborno, secuestro, tomas de población y otras), que amedrentara a la sociedad civil, y la otra característica, una fuerza física conformada entre unos 15.000 a 17.000 combatientes en distintos frentes (65); Igualmente presentan normas como la ley 002, y una economía fuerte, pero además, necesitaban alcanzar otros aspectos que esperaban lograr en la mesa de negociación.

El 14 de octubre de 1998 el presidente Andrés Pastrana les concede a las FARC el reconocimiento de organización política y pide suspender la captura contra los voceros guerrilleros; de aquí en adelante el camino quedó expedito para la construcción de su pretensión.

Territorialmente el Estado legítimo empieza a ceder frente a ese otro "Estado", se aceptó negociar en medio del conflicto y se concedió una "zona de despeje" (territorialización) de $42.000 \mathrm{~km}^{2}$, más grande que Salvador, Suiza, o Israel, con cinco municipios: San Vicente del Caguán (Caquetá), que se convirtió en la capital y sede durante los tres años de negociación y los otros cuatro municipios integrantes: Mesetas, La Macarena, Uribe y Vistahermosa. Estos municipios en su jurisdicción se fortalecieron militarmente ya que se convirtieron en una zona estratégica, refugio de secuestrados, planeación de ataques, entrenamiento y contrabando de armas. Pero lo insólito fue el ejercicio de soberanía en dicho territorio como:

- Identificación de toda persona nacional o extranjera que llegara a su territorio y sólo con un permiso para estar en ella.

- La no presencia en los cielos de naves en su territorio, sin autorización o conocimiento de la FARC

- La desmilitarización de las zonas y salida de autoridades legítimas del Estado colombiano

- La utilización de emblemas, símbolos, uniformes, himnos y banderas mostrados y utilizados por la FARC.

- La no invasión de las fuerzas militares en el Caguán

Además de esto, dieron normas para el país, como la ley 002 sobre tributación, con siete considerandos y tres artículos resolutivos: "El grupo guerrillero advierte que aquellas personas naturales o jurídicas que posean un patrimonio superior al millón de dólares deberán 
pagar un impuesto a las FARC, "Presentarse" para efectuar el pago o someterse a un segundo aviso a un "aumento" en el monto del "tributo" $y$, en su defecto, a una " retención" indefinida hasta que el pago se realice" (¿A qué juegan las FARC? En Revista Semana. Mayo 1-8 de 2000 Santafé de Bogotá edición 939 p. 24). Igualmente presentaron públicamente el "Movimiento Nacional Bolivariano" (¿Algo que ver con Hugo Chávez y su política Bolivariana?), partido clandestino de la FARC con una leyenda (por Bolívar, por la paz y la soberanía nacional).

El monopolio económico lo detentan, según cálculos del ministerio de la defensa, al comprobar que reciben 23.000 millones de pesos anuales, no se sabe cuánta sea la entrada por el negocio del narcotráfico, lavado de dinero, armas y otros, Manuel Castells (1998) Ilama la globalización del crimen organizado, que según la ONU en 1994 estimó en 750.000.000.000 de dólares; son redes entrelazadas convertidas según el autor, en el aspecto central de la política y la economía en América Latina y donde Colombia no es un invitado de piedra y con esto el Estado - Nación ha perdido buena parte de su poder y entrado en crisis la soberanía nacional, es más inoperante el Estado en lo global y menos representado en lo nacional.

Internacionalmente buscan el reconocimiento de beligerancia (estatus político), como una lucha de poder a poder (de un Estado contra otro Estado). En diciembre de 1998 Phill Chicola, subsecretario de Estado para asuntos latinoamericanos de USA se reúne en San José de Costa Rica con Raúl Reyes, vocero de la guerrilla y un delegado del gobierno de Colombia. Cuando hizo crisis el proceso en abril del
2002, los diez países facilitadores: Canadá, Cuba, España, Francia, Italia, México, Noruega, Suecia, Suiza y Venezuela y la Unión Europea (UE), piden a la guerrilla bajar la intensidad al conflicto, no violar los derechos humanos y buscar el cese del fuego y de hostilidades, y la ONU, envía a su representante James Lemoyne como intermediario. Es aquí donde se hace evidente la globalización, ya que se observa el funcionamiento en red tanto de la FARC como del Estado Colombiano, pues los asuntos no son solo de resolución nacional sino también transnacional.

El presidente Bill Clinton visita al país el 31 de Agosto y una semana después se inicia en New York la "cumbre del milenio", donde se aprobó una ayuda de cerca de 1.700 millones de dólares, que debían ser utilizados en el PLAN COLOMBIA para la lucha contra el narcotráfico - violencia terrorismo $=$ FARC, lo cual le sirvió de pretexto a la guerrilla, para presentarlo como una intervención extranjera.

Por otra parte, a la sociedad civil la guerrilla le vendió ilusiones como la discusión sobre la generación de empleo; no es raro que la cúpula empresarial colombiana se reúna con Manuel Marulanda el 17 de Marzo/2000. Las audiencias públicas de los sectores sociales invitados por la guerrilla durante año y medio, criticaron el modelo económico y plantearon exigencias al gobierno, con todo esto las FARC buscaban congraciarse con la sociedad civil, mientras se continuaba con secuestros, muertes, desapariciones, chantajes, amenazas, ataques a zonas urbanas y rurales, amedrentamiento a los gobernantes (gobernadores- alcaldes- ediles y otras autoridades colombianas), con la violencia y el terrorismo mediante el uso de la fuerza física. 
En cuanto al monopolio de la fuerza física, supuestamente exclusivo del Estado legítimamente establecido, las FARC, poseen un cuerpo aproximado de 17.000 militantes encargados de la violencia física (guerra), para enfrentar al Estado legítimo, y aunque la versión del "Estado de seguridad", planteado por Keane John, ser liberal, es aplicable a este Estado en formación, "pensamiento Hobbesiano que justifica que la seguridad estatal descansa en un contraste dramático entre sociedad civil y guerra y que se puede prevenir la guerra por adquisición o sometimiento de un Estado a otro por Institución donde por miedo la gran mayoría consiente ser gobernada por pocos" (Keane, 1992, pp. 58-60), en este caso es la voluntad de pocos sobre muchos, además con el uso de las armas para convencer por la fuerza más no por la razón.

Se presenta una crisis de soberanía nacional ante esta nueva situación, donde un Estado legítimo se ve precisado a ceder durante esos tres años (1999-2002) en el Caguán a un "Estado en formación; objetivo político de las FARC, es tal el poder de éste recién aparecido (Estado), que siempre sacó ventajas de todo tipo, como se analizó anteriormente, hasta el fin de las conversaciones (20 febrero 2002).

\section{Según Antonio Negri:}

La soberanía moderna es singularizada en virtud del hecho de que es ejercida sobre un territorio y en relación a un pueblo. El derecho internacional está fundado en el Jus Gentium o, mejor en el derecho de soberanías que originalmente consistió en resolver conflictos entre singularidades soberanas por medio de pactos" (Negri, 1996-1997, p. 57).

El orden se vio trastocado en el territorio, el pueblo (Sociedad Civil) y el gobierno como Estado legítimo colombiano frente al Estado en formación del Caguán que con su autoridad, dialéctica, uso de la fuerza (violencia), produjo una atomización a la que se refiere Negri, con la desterritorialización en un espacio que no era sólo de 42.000 km², sino la ambición de poseerlo todo (un espacio que no tiene límites). El monopolio de la fuerza física por parte del Estado no es razón suficientemente importante en el concepto de soberanía, la globalización lo ha permitido todo y el "Estado legítimo" frente a la guerrilla no la ha podido controlar como lo plantea Castells, como la globalización del crimen organizado y sus redes e interconexión de mercados que escapan al control del Estado, las comunicaciones que la guerrilla posee, su dialéctica, su ideología y otras, no se subordinan al "Estado Legitimo". ¿Es este el tipo, acaso el tipo ideal del imperio que describe Antonio Negri, que advierte acerca de sus signos y, por ello, puestos en cuestión: política, soberanía, legitimidad, uso de la fuerza coercitiva, monopolio de la hacienda, gobernabilidad y administración.

Aunque "Espacio y Tiempo" para este intento de un "Estado en Formación " ya falló, no por ello se ha terminado la intención de lucha por el poder, pues sigue latente $y$ en cualquier momento pudiera revertir el orden nacional, pues aún se muestra el abuso de la fuerza (violencia-terrorismo); en algunos territorios nacionales se ha focalizado la guerra, las negociaciones con el "Esta- 
do Legitimo" se buscan, la aprobación y ayuda internacional no se abandona, los grupos de insurgencia (FARC-ELN) piden estatus político, mientras que los paramilitares consiguen el estatus político en negociaciones vergonzosas para el Estado colombiano, circunstancia que tiene su razón en la política de seguridad democrática y seguridad nacional con los intereses internacionales; con relación al status político como lo afirmaba en el 2003 el embajador de Estados Unidos en Colombia William Wood: "No debía dársele a las FARC, ELN y los Paras el estatus político" (El Tiempo. (2003, 5 de septiembre), Bogotá p. 1-3)

Todo lo anterior produjo una crisis de Soberanía Nacional ante la falta de gobernabilidad; la democracia se ve amenazada por la falta de seguridad nacional, presentándose una coyuntura para que surja cualquier candidato con una propuesta de seguridad democrática que será uno de los planteamientos del candidato a la presidencia 2002-2006 Álvaro Uribe Vélez, quien señaló en sus 100 puntos dicha política con una
"No debía dársele a las $F A R C, E L N$ y los Paras el estatus político" número, armas, estrategia y golpes a las fuerzas armadas; políticamente al ser partícipes de primer orden en los procesos electorales al imponer criterios a favor o en contra de determinados candidatos y obligar a que fondos del Estado fueran a parar a sus manos; privaron de la vida o tomaron rehenes políticos, para presionar al Estado a su favor, un caso de tantos, Ingrid Betancourt; igualmente movieron la agenda internacional con el fin de recibir dividendos que favorecieran el reconocimiento de un status político como un grupo beligerante ante el Estado legal, con el objetivo de formar un Estado independiente con intentos como el Caguán, narrado anteriormente, o imponer su ley en los sitios de influencia.

Estos grupos en sus comienzos presentaban una plataforma con un ideología política que los identificaba con la defensa del pueblo, de los menos favorecidos y proclamaban su lucha como una forma de independencia frente a las élites colombianas que se mantenían en el poder, que esclavizaban a los más débiles promesa de cambio resumida en su lema "mano firme, corazón grande" y que se convierte en la esperanza de un pueblo sumergido en el caos, el terrorismo, la falta de gobernabilidad, la inseguridad democrática; por ello el planteamiento de la política de defensa y seguridad democrática le dará al candidato a la presidencia Álvaro Uribe Vélez la votación que lo convertiría en el presidente de los Colombianos (2002-2006).

\subsection{PARAMILITARISMO - AUC}

\subsubsection{Surgimiento}

Los grupos guerrilleros colombianos como ELN y FARC se fortalecieron económicamente mediante el secuestro, la "vacuna" y especialmente el narcotráfico; militarmente, cuando crecieron en y entregaban la economía del pueblo colombiano a los norteamericanos o capitales foráneos, que usufructuaban la riqueza nacional y que imponían grandes cargas como la deuda externa, con protagonistas de primer orden como el FMI, el BM, la OMC, factores conducentes a la entrega de la soberanía nacional, al recibir imposiciones que tenían que ser cumplidas por el Estado colombiano so pena de no recibir aprobación internacional, no ser certificados por los USA, negación de préstamos, o de algunas ayudas arancelarias; pero esta reinvidicación del Estado nacional y la lucha a favor de los pobres fue deteriorándose, desplazándose hacia el interés económico de dichos grupos que les deja el narcotráfico, que llena sus arcas con miles de millones de dólares con los cuales desafían la legalidad del Estado legítimamente constituido. 
Por otra parte, estos grupos además de su poder económico, militar y político emplean el chantaje, ataque a la propiedad privada, una dialéctica controvertida mostrándose como buscadores de paz y humanitarios, pero no quieren parar la guerra; a esto hay que sumarle la violencia y el terror con ejecuciones de personas, masacres, atentados a la riqueza nacional, destrucción de oleoductos, gasoductos, torres de energía, puentes, carreteras, ataques y tomas a poblaciones, que violentan la nación colombiana y violan los protocolos como el de Ginebra II del D.I.H., no respetan ninguna ley internacional pero si hacen su propia ley, para crear un vacío de poder en el Estado colombiano.

La guerrilla ha tenido un crecimiento numérico descomunal, posee un ejército propio con combatientes a sueldo, una economía financiada por el narcotráfico, que trae como consecuencias mayor dificultad en la negociación y una posible desmovilización inmediata o por lo menos a mediano plazo. Así ante el vacío de poder del Estado aparecen los paramilitares como una fuerza autodefensiva que se convertirá en una empresa militar ante los abusos de la guerrilla, descripción que hace Mauricio Romero en Paramilitares y autodefensas:

Estos hombres son empresarios en el sentido en que proveen de un producto - la violencia o la amenaza de violencia - y pueden actuar como agentes de otros o a título propio. Ellos intimidan, protegen, recolectan información, saldan disputas, dan garantías, hacen cumplir contratos y cobran impuestos, entre otras actividades. (Romero, 2005, p.57)

Se desarrollan en un espacio rural citadino y con una relación de terratenientes, ganaderos, agricultores, comerciantes, ejército, políticos, y condescendencia del Estado colombiano, que legitimó su creación en 1965, o la ley 48 de 1968 derogada por Virgilio Barco, que permitía y autorizaba a las fuerzas armadas a conformar grupos de autodefensa o las cooperativas de vigilancia y seguridad rural, las famosas convivir creadas el 11 de Febrero de 1994. El Tiempo las describió así:

Por definición oficial, se trataba de servicios especiales de vigilancia que operarían en zonas de alto riesgo "para devolver la tranquilidad y convertirse en aliados de la fuerza pública". Eran redes de información para denunciar los hechos de alteración del orden público. En total funcionaban 507 con 3699 hombres, la inversión se estimó en 31.802 millones de pesos. Tras encontrársele armas como subametralladoras, escopetas de repetición y fusiles fueron desarticuladas a partir de 1997 (EL Tiempo. (2006, 11 de febrero), ¿Propuesta de ganaderos revive las convivir? Bogotá. Pp.1-4)

El origen del paramilitarismo se remonta hacia 1962 cuando el gobierno de los Estados Unidos con el general Yarborough, investigador de la escuela de guerra de Fort Bragg entrega un suplemento secreto al gobierno colombiano descrito por el CINEP

Debe crearse ya mismo un equipo en dicho país, para seleccionar personal civil y militar con miras a un entrenamiento clandestino en operaciones de represión, por si se necesitaren después. Esto debe hacerse con miras a desarrollar una estructura cívicomilitar que se explote en la eventualidad de que el sistema de seguridad interna de Colombia se deteriore más. Esta estructura se usará para presionar los cambios que sabemos van a ser necesarios para poner en acción funciones de contra-agentes y contrapropaganda $y$, en la medida en que se necesite, impulsar sabotajes y/o actividades terroristas paramilitares contra conocidos partidarios del comunismo. Los Estados Unidos deben apoyar esto 
(...) también recomendaba procedimientos y técnicas de interrogatorios que incluyeran sodio, pentotal y uso de polígrafos (...) para arrancarles información a pedazos (CINEP. 2004, p.431)

Con la venia de los Estados Unidos, el Estado colombiano decide sacar disposiciones legales dadas en 1965 y 1968 para crear el paramilitarismo y con base en ellas, hacia finales de los años 70 y comienzos de los 80 se establece dicha organización, descripción que presenta Eduardo Pizarro Leongómez en entrevista hecha a Carlos Castaño (http://www. accubec.org):

Por esos días a finales de 1982, se dio la primera reunión de ganaderos, agricultores y comerciantes de la región. Cerca de 250 empresarios se organizaron para defenderse de los atropellos de la guerriIla con base en las disposiciones legales de 1965 y 1968 que permitían a los ciudadanos portar armas con salvoconductos. EI espíritu de la ley pretendía que los ciudadanos se organizaran y cuidaran sus predios con colaboración de las fuerzas armadas. Como era algo legal surgió la primera asociación de autodefensa colectiva, ACDEGAM (Asociación Campesina de Ganaderos

"Yo soy medio puritano y confieso que no fue fácil tomar la decisión. Acepté la financiación de algunos frentes de la autodefensa con el dinero del narcotráfico y escribí en mi diario: Sería cometer el peor error de mi vida o hacerlo irremediable de acuerdo a las circunstancias" y Agricultores del Magda-

lena Medio). La reunión se efectuó en Medellín, porque el $70 \%$ de ellos no podía regresar a las fincas (Pizarro, 2004, p.120)

El núcleo inicial de las ACCU daría paso a la formación de las AUC en 1994 con un jefe único Carlos Castaño quien confirmó su creación el 18 de Abril de 1997: “Las AUC son obra mía, y nadie creyó en ellas al comienzo" (Aranguren, 2001, p. 201)
Las autodefensas establecieron principios que son enumerados en el libro Una democracia asediada y de los cuales se destacan: 1. Tener definidos sus principios antisubversivos y una clara proyección política. 2. No abandonar su lucha mientras la guerrilla permanezca en pie de guerra, ni defeccionar ante los obstáculos que en decurso del conflicto se presenten; (...). 4. No involucrar sus frentes en actividades del narcotráfico (...). 7. Definir las Autodefensas Unidas de Colombia como un movimiento político-militar de carácter antisubversivo en ejercicio del derecho a la legítima defensa, que reclama transformaciones del Estado, pero no atenta contra él (...). 10. Se mantendrá siempre la unidad al interior de las AUC. (Pizarro, 2004. p.122)

Con estos principios buscan tener status político, una defensa de Estado, una participación política, no involucrarse en problemas de narcotráfico y la lucha antiguerrillera con el fin de recibir el beneplácito internacional especialmente de los Estados Unidos.

En el caso concreto de la participación de las AUC en el narcotráfico es el mismo Carlos Castaño quien toma la decisión de involucrarse en este negocio ilegal, como una forma de financiar la guerra; faltando así a uno de sus principios reseñado como el número 4 , así lo describe Castaño: “Yo soy medio puritano y confieso que no fue fácil tomar la decisión. Acepté la financiación de algunos frentes de la autodefensa con el dinero del narcotráfico y escribí en mi diario: Sería cometer el peor error de mi vida o hacerlo irremediable de acuerdo a las circunstancias". (Aranguren, 2001, p.205). 
Pero, además, se van a aliar con narcotraficantes para controlar la cadena productiva; y agregaron otra actividad ilegal de enormes resultados económicos como el robo de la gasolina. Así crecieron por todo el país estableciéndose en el Magdalena Medio, Córdoba, Putumayo, Urabá, Meta, incluso establece una capital antisubversiva: Puerto Boyacá; y como afirmaba Castaño donde "haya guerrilla allí estaremos".

Con la llegada de los paramilitares (AUC) y su objetivo de mantener el "Status quo" la definición de un mando general en la cabeza de Carlos Castaño y Salvatore Mancuso, la descentralización en grupos regionales que se distribuyen por todo el país con un centralismo de mando, programas, estatutos, búsqueda de legitimación y status político y una federalización política se da origen a la creación de las AUC.

\subsubsection{Poder Paramilitar}

Ante el reconocimiento internacional de Estados Unidos y el beneplácito del Estado colombiano que veía en su creación la defensa del Estado y llenar el vacío de poder en muchas regiones de la geografía nacional que él no podía desempeñar, crea un monstruo que se le saldría de sus manos, resultó la cura peor que la enfermedad, pues los paramilitares llegaron a adquirir un poder inusitado por medio del uso de las armas con una fuerza coercitiva más efectiva que la del Estado legítimo, con gran número de militantes, con una dirigencia central, con un poderoso y sofisticado armamento, posesión de helicópteros, avionetas, lanchas y otras embarcaciones; además del enorme poder económico a través del narcotráfico, pagos de vacunas, compra de las mejores tierras mediante la amenaza, la coacción o por vías de hecho; la asociación con gremios económicos en cabeza de ganaderos y empresarios, su alianza con el ejército la policía y las demás fuerzas coercitivas del Estado; igualmente les dará poder el ejercicio del terror, la violencia organizada la amenaza, los espectáculos macabros como las masacres, el uso de la tortura, la forma de cometer asesinatos con elementos como motosierras para descuartizar cuerpos o cualquier otra arma que impresione por su uso, narrado en Paramilitarismo de Estado en Colombia 1988-2003:

14-Jun-88: En San Rafael, Antioquia paramilitares detuvieron y desaparecieron a 17 trabajadores de una mina en dos días, miembros todos de la Cooperativa EI Topacio y militantes de la Unión Patriótica. Los primeros once fueron sacados de dos campamentos, los restantes al día siguiente de sus viviendas. Una semana después fueron encontrados dos troncos humanos, siete brazos izquierdos, tres piernas, dos cabezas, una quijada, prendas de vestir y un machete con el que posiblemente se cometió este crimen. Los restos no fueron identificados, fueron sepultados en dos ataúdes (...)

O lo realizado el 18 de Febrero del 2000 en El Carmen de Bolívar en una de sus incursiones ejecutaron 46 campesinos:

Quien opusiera resistencia era degollado o le dañaban la cabeza a punta de golpes con un destornillador. EI llanto de la población era motivo de risas para los homicidas, tanto que montaron una parranda vallenata $y$ bebieron el licor de las tiendas desde que llegaron hasta que se fueron. Sacaron de su casa a una pequeña de tres años y le pusieron un cuchillo en el cuello para obligar a la madre a que les cocinara (...) a una niña le obligaron a comer cactus (cardón) y luego la dejaron morir de sed no sin antes violarla (...) mataban con cuchiIlo, mataban con palo, mataban con plomo, mataban ahorcados. (CINEP, 2004 p.13-290). 
El terror y la violencia ejercida por los paramilitares ha hecho que muchos campesinos (sectores rurales), caseríos y pequeños municipios tuvieran que emigrar a otros sitios incluidas las capitales colombianas, para ocasionar problemas sociopolíticos y económicos, aumentar los cinturones de miseria hasta el punto de contar aproximadamente con una población de un millón quinientos a dos millones de desplazados.

El poder paramilitar se comprueba con la caída de la cúpula del DAS; influenciado de paramilitarismo como lo señala El Tiempo del miércoles 26 de octubre:

la crisis estalló cuando se conoció una grabación según la cual el director de inteligencia, Enrique Ariza, -hombre de plena confianza de Noguera- pretendía montar unas oficina privada al servicio del paramilitarismo (...), esto llevaría al gobierno a renovar la cúpula del DAS; y este hecho tocará directamente al presidente Álvaro Uribe como lo presenta el mismo periódico “(...)
El terror y la violencia ejercida por los paramilitares ha hecho que muchos campesinos (sectores rurales), caseríos y pequeños municipios tuvieran que emigrar a otros sitios incluidas las capitales colombianas.
Algunos pensarán, además, que muy flaco favor hace Vicente Castaño como ya lo había confesado Mancuso- reitera sin escrúpulos en Semana "Podemos afirmar que tenemos más del $35 \%$ de amigos en el Congreso y para las próximas elecciones vamos a aumentar este porcentaje de amigos "y son El Polo (léase Petro y aún Navarro), Pastrana, Serpa y más de una ONG los encargados de refregar que tal fuerza parlamentaria se identifica con el gobierno y de paso respalda la elección de Uribe en su mayoría. El Tiempo advierte en su editorial del domingo (la pasada) mostró de manera harto escandalosa y en diversos frentes, que el tema paramilitar y del narcotráfico ha perneado, sin remedio, una campaña electoral que apenas empieza y promete polarizarse a extremos insólitos, de seguir las cosas como van ( $D^{\prime}$ artagnan. (2005, 8 de Junio), Pelea de Titanes, en El Tiempo. p. 1-13)

El uso de la violencia y el terror ha producido un incremento en las masacres en Colombia al pase trata de una crisis causada por un escándalo de corrupción en el cuerpo de inteligencia más cercano al jefe de Estado. EI DAS depende directamente del presidente de la república y las dos personas que estaban, hasta ayer, al mando el director, Jorge Noguera, y el subdirector, Miguel Narváez - eran de entera confianza del presidente (EI tiempo. (2005, 26 de octubre), Se Cayó la Cúpula del DAS. Bogotá. p. 1-4)

El poder paramilitar ha permeado los estamentos del Estado: ejército, policía, DAS, poderes locales, departamentales y nacionales, hasta llegó a tener su representación en el Senado como lo señala D'Artagnan en El Tiempo: sar de seis en 1997 con 30 víctimas a 83 en el año 2000 con 593 víctimas según informe del Ministerio de Defensa; también se les atribuye gran parte de los asesinatos y desapariciones de la Unión Patriótica, ataques indiscriminados contra la población civil considerada por ellos como un enemigo pues sostienen que cualquiera de ellos pueden ser aliados de la guerrilla por lo cual, con sus ataques indiscriminados han tenido que desplazarse por considerarla comunista y aún enemiga de la propiedad privada.

Los hechos anteriores los ha llevado a hacer planteamientos políticos, constituyeron incluso un partido El Movimiento 
de Restauración Nacional (MORENA), en alianza con narcotraficantes, uno de sus objetivos es oponerse a cualquier acercamiento con las negociaciones de paz entre el Estado y la guerrilla como se detectó en la población de Morales, sur de Bolívar, cuando el gobierno decretó la zona de convivencia o zona de despeje, las AUC ordenaron una marcha para protestar contra el gobierno por esta determinación, Mauricio Romero lo narra así:

Vamos a salir a decirle al presidente que no queremos el despeje. Esta concepción de $<<$ pueblo $>>$ que tiene el paramilitar, la cual no se diferencia en nada de lo que se conoce $<<$ los poderes locales $>>$, llama la atención. En este sentido los paramilitares son una expresión violenta del statu quo. Junto con el anuncio de la realización de un censo de los asistentes, también se amenazó con destierro a los que no colaboraran.

Que nadie se mueva, que vamos a censar. Todos deben apoyar la marcha, de cada casa debe salir por lo menos uno. Tenemos previsto el sitio y la ruta de salida, que les avisaremos después, porque no lo podemos decir ahora. El que no colabore no le pasa nada, pero debe salir de Morales, pues no es persona grata, ya que no defiende los intereses del pueblo. (Romero, M. p.113).

Para las AUC, las negociaciones de paz con los grupos guerrilleros, son una debilidad del Estado que ellos no pueden aceptar, porque además es una forma de reivindicar y fortalecer a la guerrilla a la cual no se le deben dar estas oportunidades, sino destruirlos totalmente, además porque ellas según su propio concepto defienden al Estado de cualquier atomización política, por ello también es difícil que progrese una negociación de paz.

En las negociaciones con el Estado para la desmovilización de los grupos paramilitares se muestra el gran poder de estos y se evidencia su fortaleza al lograr una ley llamada de "Justicia y Paz" con todos sus puntos a favor, como no conocer la verdad, no reparación a las víctimas, penas muy blandas para los infractores y todo tipo de gabelas donde siempre son ganadores, a cambio de su entrega y de deponer las armas en busca de una parte de la tan anhelada paz en Colombia. Dicha ley de "Justicia y Paz" ha sido protestada por algunas ONG nacionales y extranjeras y otras entidades internacionales. Pareciera que quisieran hacer el intento de negociar a ver cómo les va, o volver nuevamente como grupos de seguridad nacional, pues el Estado no es capaz de garantizar ésta; a cambio serán nuevamente solicitados en los sitios donde se han desmovilizado pues estos espacios tratarán de ser tomados por la guerrilla y ante ese vacío de poder del Estado legítimamente constituido reaparecerán, o bien, porque muchos volverán a sus andanzas por inconformidad con las negociaciones, otros permanecerán en la clandestinidad por no negociar con el Estado, otros serán absorbidos por el mismo Estado en empleos promovidos por él o solicitados a otros, o porque los ganaderos, empresarios, terratenientes, o las élites los vuelvan a constituir con la aprobación o no del Estado, una parte de esta situación es descrita en El Tiempo:

El fantasma de las convivir reapareció ayer con la propuesta de 500 ganaderos de crear una empresa de seguridad privada para defenderse de la guerrilla, ante la desmovilización de los grupos paramilitares.

La idea fue formulada ayer en Barrancabermeja, donde el presidente presidió un consejo de seguridad con los alcaldes de 25 municipios del Magdalena Medio, autoridades militares y un nutrido grupo de ganaderos. 
El presidente de la Asociación Gestora para el Progreso Regional (Asotigra), Fabio Camargo le dijo al primer mandatario que los ganaderos de esta región están dispuestos a armarse y trabajar como una red de cooperantes. Camargo le pidió al presidente mediar para que se les facilite la creación de un "Departamento de Seguridad" para esta zona y para conseguir el armamento a un precio económico.

El representante gremial dijo que están a punto de donar un terreno de 30 hectáreas para que ese departamento de seguridad tenga su propia sede, probablemente en el sur del Cesar, y que estaría supervisada por el ejército (...) el presidente Uribe escuchó con atención el planteamiento cuando el auditorio esperaba que le diera la "bendición" a la iniciativa, se limitó a decirle a los ganaderos que debían seguir el conducto regular ante el Ministerio de Defensa (El Tiempo. (2006, 11 de febrero), ¿Propuesta de ganaderos revive las convivir? Bogotá. p. 1-4)

La mayor demostración de poder de las autodefensas se dio cuando en el proceso de desmovilización de los paras, el gobierno para dar cumplimiento al acuerdo de Santa Fe de Ralito (15 de Julio de 2003), consideró que la fecha de desmovilización debía cumplirse el 31 de diciembre de 2005 y las autodefensas determinaron que por su gran número de posibles desmovilizados (10.000) y el tiempo tan corto era imposible su cumplimiento; entonces, el Estado reclamaba la desmovilización y además les hacía conocer que no permitiría la participación política de dichos grupos y, por lo tanto, exige perentoriamente:

No existe ninguna razón válida para que se suspendan las desmovilizaciones de estos grupos. Quienes se nieguen a desmovilizarse de manera voluntaria serán enfrentados militarmente ( El Tiempo. (2005, 2c de noviembre) Paras retan al gobierno con plazo para desmovilizaciones. Bogotá, p. 1-4); en otra ocasión dirigiéndose el presidente al director de la policía, General Jorge Daniel Castro: Capture a los integrantes de los grupos de autodefensas que intervengan en política, si el señor (Ernesto) Báez, mientras no se culmine este proceso y no tenga el visto bueno de la justicia, y no se hayan desmovilizado todos los integrantes de su grupo, va a intervenir en política en Pácora, Salamina, Aguadas, o en cualquiera de esos municipios de Caldas, captúrelo, General Castro, bajo mi responsabilidad política (Semana. (2005, 7 de noviembre), "Mano dura, vozarrón grande". p.40)

Pero más vehemente fue la respuesta de las AUC:

Que no nos amenacen con el aparato militar del Estado porque ese aparato no ha podido solucionar el problema del conflicto armado en Colombia en 40 años (...) desde hoy declaramos, pase lo que pase que es imposible cumplir con esa fecha (31 de diciembre)" (EI Tiempo. (2005, 2 de noviembre), "Paras retan al gobierno con plazo para desmovilizaciones". Bogotá. pp.1-4)

La respuesta de las AUC al gobierno colombiano es un reto al Estado legítimo, al que supuestamente según uno de sus principios deben defender, critican a su aparato militar por su ineptitud, y se sienten tan poderosos que hacen prácticamente una declaración de guerra, "cría cuervos y te sacarán los ojos", o sea el hijo (AUC) reta al padre (Estado) como lo señala la Corte Interamericana de Derechos Humanos en sentencia proferida el 15 de septiembre de 2005 en el caso de la “masacre de Mapiripán vs. Colombia, en el numeral 14 de su parte resolutiva que ordena publicar al Estado en el término 
de seis meses, en un diario de circulación Nacional y su diario oficial la sentencia sobre hechos probados sobre la responsabilidad internacional del Estado en dicha masacre, al señalar la creación y participación directa del Estado en los grupos ilegales llamados paramilitares. Así se describe en el numeral 96.1 de dicha sentencia:

El 24 de diciembre de 1965, el Estado emitió el decreto legislativo 3398, "por el se organiza la defensa Nacional", el cual tenía una vigencia transitoria, pero que fue adoptado como legislación permanente mediante la ley 48 de 1968 (con excepción de los artículos 30 y 34). Los artículos 25 y 33 del referido decreto legislativo dieron fundamento legal a la creación de los grupos de autodefensa (...)" al respecto el artículo 25 estipuló que "todos los Colombianos, hombres y mujeres, no comprendidos en el llamamiento al servicio militar obligatorio, podían ser utilizados por el gobierno en actividades y trabajos con los cuales contribuyeran al restablecimiento de la normalidad. Así mismo, en el parágrafo 3 del mencionado artículo 33 se dispuso que el Ministerio de Defensa Nacional por conducto de los comandos autorizados, podía amparar, cuando lo estime conveniente, como uso privativo de las fuerzas armadas. Los grupos de autodefensa "se conformaron de manera legal al amparo de las citadas normas, por lo cual contaba con el apoyo de las autoridades estatales (INFORMACIÓN INSTITUCIONAL. Ministerio de Defensa Nacional, cumplimiento de sentencia ordenado por la Corte Interamericana de Derechos Humanos. Caso de la "Masacre de Mapiripán". Publicación presentada en El Tiempo del día domingo 9 de Abril de 2006. Separata (96.1), p.1)

Así el hijo (AUC) considera una bravata de su padre (Estado) y, por lo tanto, no están dispuestos a cumplir; decisión que toman porque no están vencidos; de ahí que impongan su criterio en la mesa de negociaciones, cuando Alfredo Rangel resumió la presentación de su libro $\mathrm{El}$ Poder Paramilitar (Planeta):

No obstante, en el pináculo de su poder militar, económico, social y político, los paramilitares han decidido iniciar conversaciones con el gobierno del presidente Álvaro Uribe Vélez, con el fin de acordar las condiciones para su propia desmovilización. Varias razones parecen haber confluido para tomar que los paramilitares hubieran tomado esta decisión en el preciso momento en que son más fuertes y cuando sus posibilidades de fortalecimiento y expansión son poco menos que ilimitadas, sin haber sido derrotados previamente por el Estado ni tampoco haber derrotado la guerrilla (Rangel, 2005, p. 10)

El poderío mostrado en las negociaciones por los grupos paramilitares ha llevado incluso a enfrentamientos políticos entre el presidente Álvaro Uribe y César Gaviria, quien considera que la ley de Justicia y Paz es una ley dañina e impune para el país en declaración dada a la W. FM:

Denunció que ciertas mafias se han apoderado de las administraciones regionales ante lo cual el presidente Uribe "se ve como muy cómodo". Dijo que no se trata ya sólo temas de droga, sino que se han apoderado del cobro de impuestos, de las loterías y del juego del chance (EI Tiempo. (2005, 14 de junio), "Nuevas pullas entre Gaviria y Uribe". Bogotá. Pp.1-18)

Además los grupos paramilitares son poseedores de una gran riqueza económica que han conseguido a través del narcotráfico, contrabando, posesión de grandes propiedades de tierra, bienes inmuebles, gasolina que le roban al 
Estado, dinero de chantaje, vacunas y otros, además, del terror y la violencia por ellos practicada; todo ello los hace supremamente poderosos, capaces de imponer condiciones gananciosas a su favor sin dar nada pero exigiéndolo todo. ¿Qué podrá suceder cuando el Estado no cumpla sus promesas? ¿Su desmovilización es una solución, o, se convierte en otro gran problema? ¿Qué sucederá con tan alto número de desmovilizados? ¿Podrá el Estado llenar ese vacío de poder impuesto por las AUC? ¿Cómo será aprovechada la desmovilización por los insurgentes? ¿Es muy posible que los paramilitares no desaparezcan del todo? Hay muchas preguntas que quedan por resolver.

Grupos como los narcotraficantes, la insurgencia, los paramilitares, la delincuencia común y los sucesos internacionales se convierten en un reto para el Estado legítimamente constituido, hacen que en ocasiones viva momentos difíciles por estos aspectos internos o externos que deterioran y menoscaban la soberanía nacional pues hacen crisis en la democracia Colombiana.

\subsection{SOBERANÍA NACIONAL}

Las relaciones que se establecen entre Estados y las que acuerda un Estado entre gobernantes y gobernados, se conocen como autodeterminación y autonomía de los pueblos y son las que determinan la legitimación de la soberanía nacional (Negri, 1996-1997, P. 57-64) $^{1}$

Los Estados quieren legitimar su soberanía bien sea en lo interior o lo exterior, pues estos hechos se vinculan estrechamente en la globalización, presentan interdependencia entre ambos; pero no separados, puesto que los Estados no están solos, y las decisiones tomadas por él, tienen una repercusión transnacional. En su dinámica moderna los Estados tendrán relaciones en la administración, el territorio o espacio, pueblo, autoridad, porque el viejo orden soberano hace énfasis en muchos elementos, algunos ejemplos pueden ayudarnos en la visión mundial del nuevo orden (Nuevo Orden Imperial), en el cual, lo que para unos es, para otros no, como en el caso de las dos guerras en el Golfo Pérsico. ¿Cuál es la soberanía legítima? ¿La de Estados Unidos o la de Irak? ¿Qué tipo de soberanía se defiende, la del agresor o la del agredido? Más cuando Irak es atacado sin causa justa y cómo la ONU con su poder de árbitro mundial fue relegada a un simple espectador.

Con la globalización la soberanía pierde legitimidad, la moneda, las políticas económicas, las relaciones internacionales abocan cada vez más a ceder frente a determinadas circunstancias que no son más que relaciones de poder. Hay que pertenecer a bloques poderosos que permitan defender en algunas circunstancias lo mínimo, con tal, de no ser arrasado en su política, comunicaciones, cultura, economía, tecnología, conocimiento, éste como una nueva forma de poder del país que lo posee frente a quien no lo tiene. Las comunicaciones no tienen un espacio delimitado y entran sin ningún escrúpulo a entrometerse dentro de cualquier Estado, el idioma y especialmente el inglés, universalizó el mundo en lengua y con ello el poder que esto conlleva. De ahí que la crisis de la soberanía nacional como una relación de poder tenga que ser reconsiderada y evaluada bajo otros parámetros diferentes al antiguo paradigma. Los Estados en la globalización ceden mucho de lo suyo. Esperemos qué 
nos deja el tiempo ante estos hechos de crisis internacional y cómo pudiera ser el Nuevo Imperio, ante la crisis del espacio político.

Para el presente trabajo Soberanía Nacional será la autonomía de un Estado en ejercicio del poder público y su relación entre gobernantes y gobernados con un territorio y una administración de autoridad, con un monopolio del uso de la fuerza física, en el aspecto interno; y la relación transnacional de convivencia en condiciones de libertad, igualdad, justicia y tolerancia con otros Estados en el aspecto externo. La constitución colombiana lo presenta en su preámbulo: “El pueblo de Colombia, en ejercicio de su poder soberano (...)"; en el artículo tercero: “La soberanía reside exclusivamente en el pueblo, del cual emana el poder público. El pueblo la ejerce en forma directa o por medio de sus representantes, en los términos que la constitución establece (...)" y en el artículo noveno: "Las relaciones exteriores del Estado se fundamentan en la Soberanía Nacional, en el respeto a la autodeterminación de los pueblos y en el reconocimiento de los principios del derecho internacional aceptado por Colombia (...)" (COLOMBIA, (2006), Constitución Política, Bogotá, Legis). Por lo tanto, Soberanía Nacional son las relaciones internas y externas de un Estado legítimamente constituido; ésta puede debilitarse, entrar en crisis o desaparecer, por haber colapsado, por situaciones coyunturales no solucionadas internamente, como una guerra civil, corrupción de sus entes administrativos u otros grupos de poder (élites políticas, militares, guerrilla, narcotráfico, paramilitares), o, externamente por la invasión de uno u otros Estados por uso de la fuerza; por el dominio económico impuesto, deu- da externa a través de entidades como el $\mathrm{FMI}, \mathrm{BM}, \mathrm{OMC}$, que llevan a una entrega de la Soberanía Nacional con negociaciones ignominiosas que condicionan la libertad de la nación colombiana. Algunos de los hechos mencionados han sumergido al Estado legítimo colombiano en una crisis de Soberanía Nacional y, por tanto, la democracia se encuentra amenazada por sucesos internos y transnacionales (globalización).

\subsubsection{Sucesos internos que atentan contra la Soberanía Nacional}

Colombia sufre internamente una serie de amenazas que atentan contra la democracia y la Soberanía Nacional que la sumerge en una crisis de gobernabilidad y legitimidad. Según la Política de Defensa y Seguridad Democrática dichas amenazas son:

en el pueblo, del

cual emana el poder público. $\mathrm{El}$ pueblo la ejerce en forma directa $o$ por medio de sus representantes, en los términos que la constitución establece (...)"

La seguridad de los ciudadanos de la democracia y de los intereses vitales de la Nación, como los establece la Constitución Política, está hoy expuesta a una serie de graves amenazas, ligadas entre sí y con frecuencia de carácter transnacional. No son estos los únicos peligros que enfrenta la democracia colombiana. La corrupción, por ejemplo, es igualmente una amenaza grave y será combatida de la manera más decidida por el Gobierno Nacional, como lo será la criminalidad común. Pero las siguientes amenazas constituyen un riesgo inmediato para la Nación, las instituciones democráticas y la vida de los colombianos: el terrorismo, el negocio de las drogas ilícitas, las finanzas ilícitas, el tráfico de armas, municiones y explosivos, el secuestro y la extorsión, el homicidio" (Ministerio de Defensa Nacional, 2003, P. 24) 
Prácticamente la corrupción y el narcotráfico permean a todas las demás; ejemplo de corrupción dentro del mismo gobierno del presidente Álvaro Uribe Vélez lo muestra la crisis del DAS, descrita en la revista Cambio con la relación a las acusaciones dirigidas contra Jorge Aurelio Noguera Cote, exdirector del DAS, por Rafael García, exdirector de informática del DAS presentada así:

García aseguró que el entonces director del DAS Jorge Aurelio Noguera Cote, tenía una relación estrecha con Rodrigo Tovar Pupo, Jorge 40 y reveló que el $10 \%$ del valor de los más jugosos contratos de la entidad iban a parar a las arcas del jefe paramilitar. Sus denuncias no se detuvieron ahí. También relató cómo altos funcionarios del DAS habían entregado a las autodefensas de la Costa Atlántica una lista con los nombres de sindicalistas, estudiantes y dirigentes de izquierda que luego fueron asesinados, y confesó haber participado en la preparación de un fraude que contribuyó a elegir a 7 congresistas en 2002 y a obtener cerca de 300.000 votos para favorecer a Álvaro Uribe" (Cambio, (2006, 3 al 10 de Abril), "Yo Acuso" No. 666, p. 24)

Hay otro escándalo en ciernes por los secretos del Fondo Ganadero del Caquetá, por el desvío de 24.000 millones del erario que terminaron en poder de Luis Enrique Ramírez "Miki" con vinculaciones con el narcotráfico en el cartel de Medellín, procesado actualmente entre otros delitos, concierto para delinquir y lavado de activos, presentado en El Tiempo así:

La otrora anónima sociedad ubicada en un viejo edificio en Villavicencio (Meta), tiene enredados penalmente a varios empleados estatales y enfrentados públicamente al Ministro de agricultura, Andrés Felipe Arias; al gerente del Banco Agrario, César Pardo y al expresidente del Fondo para el Financiamiento del Sector Agropecuario (FINAGRO) Roger Taboada.

En un rifirrafe de acusaciones con claros visos penales, Pardo acusa a Taboada de haber autorizado millonarios desembolsos a favor de ese Fondo Ganadero, contradiciendo decisiones expresas de la junta directiva de FINAGRO, de la que Él hace parte" (El Tiempo, (2006, 16 de Abril), "Los secretos del fondo Ganadero del Caquetá", Bogotá, p.1-6)

Pero, eso son solo unas muestras de los tantos hechos de corrupción que hoy se investigan, como la adjudicación de tierras (INCODER), y el otorgamiento de créditos para favorecer a líderes paramilitares, o la infiltración de funcionarios y ex funcionarios de la DIAN en los sistemas contables para borrar listas de empresas morosas, más de 265 empresas, haciéndolas aparecer como si estuvieran a paz y salvo a cambio de un dinero que por ello cobraban.

El terrorismo y la violencia tienen al Estado contra la pared pues producen asesinatos de políticos, líderes sindicales, maestros, indígenas, campesinos, igualmente ataques a poblaciones indefensas, población rural, masacres, amenazas y chantajes que ante el terror producen desplazamientos, abandono de sus tierras y traen un nuevo problema a los sitios urbanos, al aumentar los pobladores de los cinturones de miseria, cuando allí logran asentarse, o convertirse en una población sin un lugar donde vivir, sin comida, sin asistencia médica e igualmente violentados por el medio. A toda esta violencia y terror hay que sumarle el terrorismo de Estado por la violación de los derechos humanos, por los cuales ha tenido que atender demandas internacionales por abuso de su poder, culpándosele de desapariciones, muertes selectivas de la población civil, participación con otros grupos (paramilitares), y aún la misma negligencia para actuar antes de conoci- 
dos los hechos de terrorismo, o, después por no actuar con el rigor debido con los responsables de hechos violentos atentatorios contra la dignidad humana.

El problema de las drogas ilícitas desde su cultivo que sigue en aumento, pues a la fecha de hoy (2006) aparecen 38.600 hectáreas adicionales de coca, que producen cada día más problemas ambientales por producirse en territorios de reservas forestales como el Amazonas, Sierra de la Macarena, Sierra Nevada de Santa Marta y otros sitios que son afectados con la aspersión de químicos, bien para su siembra y producción; o por el uso de ellos (glifosato) para acabar con los cultivos, lo que conlleva a un atentado ecológico por las consecuencias que puedan traer como la erosión, por la tala de bosques, la pérdida de la riqueza natural del suelo, la destrucción de la capa de ozono y la afectación, además, sobre la fauna, la flora y la salud de los seres humanos.

La exportación de estas drogas trae al país millones de dólares de contrabando, lavado de activos, empresas simuladas de legalidad, manejo de terceros (testaferros), que sirven como legalizadores de ese dinero, y con un poder de vida o muerte (sicariato), corrupción a todos los niveles, desde la sociedad civil hasta los altos mandos del Estado, presidentes, senadores y otros políticos. Igualmente militares, policías, que son comprados por narcodólares, que debilitan no solo la economía nacional, sino la estabilidad del Estado, también es negocio de los grupos insurgentes, de los paramilitares y la delincuencia común, que les sirve como sostenimiento, convirtiéndose dicho dinero en propagador del terrorismo, traspasa los límites nacionales al tomar un carácter internacional, con posiciones en contra del país ya sea por los Estados Unidos, que son los principales consumidores $y$ que atribuyen su mal a nuestro país; y también la Unión Europea y la América Latina. Eduardo Gamarra escribe:
El Estado, en Colombia, no logró controlar la basta y compleja geografía y sus instituciones fueron demasiado débiles para hacerle frente a la estructura transnacional del narcotráfico, dicho de otra forma, Colombia logró apenas una soberanía limitada sobre su territorio nacional y el narcotráfico la limitó aún más" (Gamarra, 2004, p. 249)

Generalmente todas las amenazas presentadas en Colombia son conexas y podría decirse que ninguna está suelta, por el contrario, en ocasiones fortalecidas por alianzas como la acordada entre el cartel de Cali y los paramilitares para acabar con el cartel de Medellín dirigido por Pablo Escobar.

\section{Nota}

${ }^{1}$ En "La crisis del Espacio Político", Negri expone: En la era moderna el concepto de orden político y social se aproxima al concepto de soberanía territorial y lo convierte con el tiempo en "Soberanía Nacional" y toma los dos conceptos separadamente, según él soberanía es un concepto de poder que no tiene nada por encima de sí mismo. El concepto de Soberanía moderno es singularizado por virtud de ser ejercida sobre un territorio y en relación a un pueblo con una conexión internacional a través del lus Gentium (derecho de gentes); o sea la relación con otras soberanías y su resolución de conflictos a través de pactos; pero igualmente en lo interior como una legitimación o relación entre sujetos y poder. Combinada nación y soberanía (Soberanía Nacional) a comienzos del siglo XIX se perfecciona el concepto, exaltando la conexión entre soberanía y sujetos y al mismo tiempo la potencia del todo. En la Soberanía Nacional territorio y pueblo son dos atributos y el gobierno la relación que consagra la unidad. En la política moderna (Soberanía) es una combinación de un pueblo, un territorio, una autoridad. 
El autor describe, además, que desde el punto de vista externo la soberanía se caracteriza por: el uso de la fuerza física y su monopolio, la capacidad de acuñar las normas sociales de intercambio para la reproducción (moneda), la singular estructuración de las fuerzas de comunicación (idioma nacional, sistema educativo, etc.). Los modernos Estados soberanos en su hegemonía han exportado su poder absoluto más allá de sus territorios que originalmente integraron y los modelaron dentro de las reglas de la dominación. Pero el viejo paradigma del orden soberano es sumido según el autor por un terremoto y los cambios son tan profundos y extensos, que no se sabe las direcciones de desarrollo que estos tomen, siendo el primer elemento del terremoto la desterritorialización en relación con un espacio que no tiene límites. Hay según él tres elementos para aproximarse al nuevo escenario de poder y son: la bomba, la moneda y el éter.

LA BOMBA como el reino del terror y la extensión de la nación de Soberanía Limitada para la gran mayoría de los países del mundo. El monopolio legítimo de la fuerza física cualidad de la soberanía no le pertenece a la mayoría de los Estados y este concepto está totalmente desdibujado.

LA MONEDA la describe como la construcción del mercado mundial que involucra una deconstrucción monetaria de los mercados y los contextos nacionales y regionales de regulación monetaria y sitúa los años de 1971 y 1973 cuando los Estados Unidos separaron el dólar del oro que pone fin a un largo periodo de tasa de cambio fijo, y termina con la convertibilidad, así las relaciones monetarias se subordinan a los movimientos de poderes financieros y la moneda nacional tiende a perder todas las características de soberanía. El proceso de globalización es también un poderoso agente de transformación.
EL ÉTER, sustancia de la prerrogativa soberana, son la fijación de la lengua y defensa de ella, la construcción de un sistema educativo y protección de su cultura. Los modernos sistemas de comunicación no se subordinan a la soberanía, sucede todo lo contrario. La capacidad de las comunicaciones para la desterritorialización es totalmente original, remueve aún la posibilidad de relacionar un determinado orden con un determinado espacio. Así en el éter los idiomas devienen funcionales a la circulación y disuelven toda relación de soberanía. El espacio de la comunicación está desterritorializado, es metamorfosis de los elementos de la economía política y teoría del Estado. Ante esta crisis el autor anticipa un tipo ideal de imperio que podía ser útil totalmente diferente de imperialismo.

El imperio se avizora o está en su lugar como una filosofía política y la posmodernidad nos ha advertido acerca de los signos del IMPERIO e igual el proceso constitutivo con una hibridación crecientemente fuerte cuando se considera: lo propio y lo impropio, de lo económico y lo político, de lo legal y lo ilegal; cuando las consideraciones tradicionales del derecho y lo social (no olvidan la moral) se enfrentan a la apertura del imperio.

Concluye el autor, que el quiebre de la moderna relación entre orden y espacio es una ruptura radical el signo de una mutación de paradigma. Los conceptos de política, soberanía, legitimación, administración, de ahora en adelante están en crisis sujetos a revisión pero en largos plazos abiertos al derrocamiento y la subversión, porque, no tienen más relación con el viejo paradigma de orden nacional, internacional, territorial y cosmopolita. No hay alternativas a la verticalidad del NUEVO PODER IMPERIAL. Las únicas alternativas es si pertenece a uno o a varios. Somos ciudadanos que nos preparamos para hacer pública su nueva organización internacional de las relaciones de dominación. 


\section{Referencias}

ARANGUREN, Molina, M. (2001), Mi confesión. Carlos Castaño revela sus secretos, Bogotá, Oveja Negra. p.201

BLANQUERT, J-M y Gros, C. (Comps) 2002, Las dos Colombias. Análisis macroeconómico del narcotráfico en la economía Colombiana, Bogotá, Norma. p.399

BOBBIO, N. (1997), Estado, Gobierno y Sociedad. México, Fondo de Cultura Económica pp. 129-130

CASTELLS, M. (1998, Marzo), ¿Hacia el Estado Red? Globalización Económica e Instituciones Políticas en la Era de la Información. Ponencia presentada en el Seminario sobre Sociedad y Reforma del Estado. Brasil

CINEP. (2004), Deuda con la Humanidad. Paramilitarismo de Estado. 1998-2003. Banco de Datos de Violencia Política. Códice. Bogotá, p.431

COLOMBIA, (2006), Constitución Política, Bogotá, Legis

COLOMBIA, MINISTERIO DE DEFENSA NACIONAL, (2003), Política de Defensa y Seguridad Democrática, p.24

D'ARTAGNAN. (2005, 8 de Junio), Pelea de Titanes, en El Tiempo. P.1-13

EL TIEMPO, (2006, 16 de Abril), "Los secretos del Fondo Ganadero del Caquetá", Bogotá, p.1-6

EL TIEMPO. (2003, 5 de Septiembre), Bogotá p.1-3

EL TIEMPO. (2005, 14 de Junio), “Nuevas pullas entre Gaviria y Uribe". Bogotá p. 1-18

EL TIEMPO. (2005, 2 de Noviembre), "Paras retan al gobierno con plazo para desmovilizaciones". Bogotá. P.1-4

EL TIEMPO. (2005, 26 de Octubre), Se Cayó La Cúpula del DAS. Bogotá. p. 1-4

EL TIEMPO. (2006, 11 de Febrero), ¿Propuesta de ganaderos revive las convivir? Bogotá. p. 1-4

ELÍAS, N. (1989), El Progreso de la Civilización, Madrid, Fondo de cultura Económica p. 345 y siguientes

GAMARRA, Eduardo. "La Democracia y las drogas en América Latina y el Caribe". En: La Democracia en América Latina contribuciones para el debate. Publicado por el programa de las Naciones Unidas para el desarrollo (EL PNUD), Buenos Aires, septiembre. 2004. P.249

INFORMACIÓN INSTITUCIONAL. MINISTERIO DE DEFENSA NACIONAL, cumplimiento de sentencia ordenado por la Corte Interamericana de Derechos Humanos. Caso de la "Masacre de Mapiripán". Publicación presentada en El Tiempo domingo 9 de Abril de 2006. Separata (96.1). p.1

KEANE, J. (1992), Recordando a los muertos. Sociedad Civil y Estado desde Hobbes hasta Marx y más allá, Madrid, pp.58-60

LEAL, Buitrago, F. (2002), La Seguridad Nacional a la deriva, del Frente Nacional a la postguerra fría, Colombia, Alfa Omega p.127

LÓPEZ, Restrepo, A. (2000), Prohibición a la guerra: El narcotráfico colombiano en el siglo XX. En Colombia cambio de siglo. Balances y perspectivas IEPRI. Santa Fe de Bogotá, Planeta, p. 97

NEGRI, A. (Primavera-Verano 1996-1997), La crisis del ejercicio Político, Revista Viento del Sur, \# 15, Junio 1990, Buenos Aires. Tomado de: Revista Doxa \#16, Buenos Aires, Argentina p.57

NIETZSCHE, F. (1982), Así habló Zaratustra, Bogotá, Oveja Negra pp. 72-73

PIZARRO, Leongómez, E. (2004), Una Democracia asediada. Balance y perspectivas del conflicto armado en Colombia. Bogotá, Norma, p. 120

RANGEL, Alfredo. Lo justo y lo necesario con el paramilitarismo. En: Lecturas Dominicales El Tiempo sábado 8 de octubre de 2005 p.10

REVISTA CAMBIO, (2006,3 al 10 de Abril), "Yo Acuso" $\# 666$, p.24
REVISTA SEMANA. (2005, 7 de noviembre), "Mano dura, vozarrón grande" p. 40

REVISTA SEMANA: ¿A OUÉ JUEGAN LAS FARC? MAYO 1-8 DE 2000 SANTAFÉ DE BOGOTÁ EDICIÓN 939 P. 24

ROMERO, M. (2005), Paramilitares y Autodefensas 1982 2003. Bogotá IEPRI. p.57

TORRES, E, y Sarmiento, A. (1998), Rehenes de la mafia, Santafé de Bogotá, Intermedio editores 1998 pp. 257-258

WALZER, M. (1994 Abril-Junio), La Idea de la Sociedad Civil en: Revista Ciencia Política \# 35 p.48

WEBER, M. La política como vocación en: “El Político y el Científico", Alianza Editorial, Madrid 1980 p.183 